\title{
Characteristics and outcomes of out-of-hospital cardiac arrest in Zhejiang Province
}

\author{
Min Fei, Wen-wei Cai, Sheng-ang Zhou \\ Department of Emergency Medicine, Zhejiang Provincial People's Hospital, Hangzhou, China
}

Corresponding Author: Min Fei, Email:fammy2001@163.com

\author{
World J Emerg Med 2018;9(2):141-143 \\ DOI: 10.5847/wjem.j.1920-8642.2018.02.010
}

\section{Dear editor,}

China has undergone tremendous economic growth, but there still remains much room for improvement in emergency medical service (EMS) system. ${ }^{[1]}$ The EMS in China comprises of three parts: the pre-hospital emergency service, the emergency department, and the intensive care unit. Not much is known about the exact numbers of out-of-hospital cardiac arrest (OHCA) across the whole of China, though there are reports from specific provinces. Due to differences in methods of data collection and data definitions, it is difficult to make comparisons among provinces or summarize the total data, therefore, it is necessary to describe characteristics and outcomes of OHCA within one province.

Zhejiang province located on China's southeastern coast covers a total land area of 101,800 square kilometers with a population of approximately 8.8 million at the end of 2014. There were 689 ambulances in 68 emergency centers and only $28.2 \%$ of ambulances are equipped with defibrillators. An ambulance includes 3 EMS staff members, including at least 1 emergency physician. Emergency physicians are trained to perform various resuscitation methods, like semi-automated external defibrillators, intubation, insertion of a peripheral intravenous line, and administration of drugs such as epinephrine in situations of cardiac arrest.

Zhejiang Provincial People's Hospital is one of the largest comprehensive hospitals in Zhejiang province, which provides medical care with more than 2,000 beds and has 150,000 visits to emergency departments annually. Ningbo and Shaoxing are two of the most important cities in Zhejiang province. Ningbo EMS Center serves a population of approximately 5,830,000 around Ningbo City, while Shaoxing EMS Center serves approximately $4,430,000$ people around Shaoxing City.

Our study aimed to summarize characteristics and outcomes of OHCA in Zhejiang province, based on the OHCA cases presenting to Zhejiang Provincial People's Hospital, Ningbo EMS Center, and Shaoxing EMS Center.

\section{METHODS \\ Study setting and design}

This is an observational, retrospective, multi-center study based on the identification and analysis of records of OHCA patients during the period between January 1, 2012 and January 31, 2016. The data was collected from the three EMS centers. Data was collected in accordance with the recommended guidelines ${ }^{[2]}$ for uniform reporting of data from out-of-hospital cardiac arrest, including sex, age, past medical history, location of arrest, course of resuscitation, presence of witnesses, pre-hospital drug administration, first arrest rhythm, bystander cardiopulmonary resuscitation (CPR), return of spontaneous circulation (ROSC), hospital admission, and hospital discharge. After completion by the EMS personnel, the data form was integrated into the registry system, and checked by the investigators. If the data sheet was incomplete, the relevant EMS personnel were contacted and questioned for data completion.

The 2010 American Heart Association Guidelines for Cardiopulmonary Resuscitation and Emergency Cardiovascular Care ${ }^{[3]}$ was adapted for the resuscitation protocol. Bystander CPR included chest compressiononly CPR and conventional CPR with rescue breathing. ROSC refers to the regaining of palpable pulse. 


\section{Statistical analysis}

The statistical package for social sciences (SPSS), version 19.0, (IBM, New York, New York, USA) was used for data entry and analyses. Descriptive analyses were carried out by calculating the number and percentage for categorical variables, whereas mean $\pm \mathrm{SD}$ were calculated for continuous variables.

\section{RESULTS}

During the study period, there were a total of 353 OHCA cases recorded in the three EMS centers. Twentyone $(5.9 \%)$ cases were excluded because they were transferred to EMS centers not by ambulances thus lacking prehospital records. Demographic data including age, sex and past medical history are listed in Table 1. More than half OHCA occurred in home. A total of $253(76.2 \%)$ patients were witnessed by bystanders,

Table 1. Characteristics of patients with OHCA, $n(\%)$

\begin{tabular}{|c|c|}
\hline Characteristics & $\mathrm{OHCA}(n=332)$ \\
\hline Age $[$ mean $( \pm \mathrm{SD})]$ (years) & $58( \pm 20.8)$ \\
\hline Male sex & $233(70.2)$ \\
\hline \multicolumn{2}{|l|}{ Past medical history } \\
\hline Heart disease & $60(18.1)$ \\
\hline Hypertension & $61(18.4)$ \\
\hline Diabetes mellitus & $25(7.5)$ \\
\hline Cancer & $15(4.5)$ \\
\hline Chronic obstructive pulmonary disease & $14(4.2)$ \\
\hline \multicolumn{2}{|l|}{ Location of arrest } \\
\hline Home residence & $220(66.3)$ \\
\hline Healthcare facility & $8(2.4)$ \\
\hline Public/commercial building & $27(8.1)$ \\
\hline Street/highway & $44(13.3)$ \\
\hline Industrial place & $18(5.4)$ \\
\hline Place of recreation & $9(2.7)$ \\
\hline Others & $6(1.8)$ \\
\hline \multicolumn{2}{|l|}{ Arrest witnessed } \\
\hline Arrest witnessed by bystander & $253(76.2)$ \\
\hline Arrest witnessed by EMS personnel & $16(4.8)$ \\
\hline Arrest not witnessed & $63(19.0)$ \\
\hline \multicolumn{2}{|l|}{ Pre-hospital resuscitation } \\
\hline CPR by bystander & $11(3.3)$ \\
\hline CPR by EMS personnel & $283(85.2)$ \\
\hline CPR not attempted & $38(11.4)$ \\
\hline Defibrillation attempted & $28(8.4)$ \\
\hline Defibrillation not attempted & $304(91.6)$ \\
\hline Intubation attempted & $60(18.1)$ \\
\hline Intubation not attempted & $272(81.9)$ \\
\hline \multicolumn{2}{|l|}{ Pre-hospital drug administration } \\
\hline Epinephrine & $173(52.1)$ \\
\hline Sodium bicarbonate & $20(6.0)$ \\
\hline Atropine & $6(1.8)$ \\
\hline \multicolumn{2}{|l|}{ First arrest rhythm } \\
\hline $\mathrm{VF} / \mathrm{VT}$ & $23(6.9)$ \\
\hline PEA & $19(5.7)$ \\
\hline Asystole & $244(73.5)$ \\
\hline Unknown & $46(13.9)$ \\
\hline
\end{tabular}

while bystander CPR was performed only in $11(3.3 \%)$ cases. CPR was mainly performed by EMS personnel $(283,85.2 \%)$. Only $28(8.4 \%)$ patients underwent prehospital defibrillation, and pre-hospital intubations was attempted in $60(18.1 \%)$ patients. Epinephrine was the most frequently used drugs (52.1\%) in an out-of-hospital environment. Asystole was the predominant rhythm $(73.5 \%)$.

In this study, the arrests were classified as trauma origin and non-trauma origin (cardiac etiology, respiratory diseases, electrocution, drowning and other causes). These diagnoses were made clinically by the physician in charge in collaboration with the EMS personnel. Totally 103 (31.0\%) patients had trauma arrest and $229(69.0 \%)$ had non-trauma arrest. Cardiac etiology $(43.4 \%)$ was the top causes in the subgroup of nontrauma (Table 2).

Ten patients had ROSC at scene/en-route and 37 had ROSC at ED. Only 27 patients were admitted to the hospital. At discharge, only 7 (2.1\%) patients survived (Table 3).

\section{DISCUSSION}

OHCA is a leading cause of death in the industrialized world. ${ }^{[3,4]}$ The development of a public-access defibrillation system and revisions to CPR guidelines have increased survival rate after OHCA in some countries, but the outcomes of OHCA in China remains poor. ${ }^{[5]}$

In Zhejiang province, many efforts have been made to improve the survival rate, like reducing the EMS response time, regular CPR training for the EMS staff and emergency physicians, and early implementation of the current CPR guidelines. Because of the lack of favorable evidence, sodium bicarbonate administration

Table 2. The causes of OHCA

\begin{tabular}{lc}
\hline Cause of arrest & $n(\%)$ \\
\hline Trauma & $103(31.0)$ \\
Non-trauma & $229(69.0)$ \\
Cardiac etiology & $144(43.4)$ \\
Respiratory & $14(4.2)$ \\
Electrocution & $6(1.8)$ \\
Drowning & $12(3.6)$ \\
Others & $53(16.0)$ \\
\hline
\end{tabular}

Table 3. Overall outcomes of OHCA

\begin{tabular}{ll}
\hline Outcomes & $n(\%)$ \\
\hline ROSC at scene/en-route & $10(3.0)$ \\
ROSC at ED & $37(11.1)$ \\
Admission to hospital & $27(8.1)$ \\
Survival to hospital discharge & $7(2.1)$ \\
\hline
\end{tabular}


during adult and pediatric CPR is not recommended, but it was still the second most used pre-hospital drug after epinephrine as a conventional equipment in ambulances, particularly in many rural areas of Zhejiang province.

In this study, we found only a small number of patients $(3.3 \%)$ received CPR performed by bystanders. The rate was lower than that reported in other Asian countries, $10.5 \%$ in United Arab Emirates, $40.2 \%$ in Japan, and $40.9 \%$ in Republic of Korea. ${ }^{[6]}$ This indicated that the basic knowledge and skills of CPR are comparatively poor in our cities, therefore it is urgent to train people to perform CPR when facing CA patients. ${ }^{[7]} \mathrm{A}$ telephoneassisted CPR program ${ }^{[8]}$ is recommended. Only $4.8 \%$ patients received pre-hospital defibrillations. The rate was also lower than that of most Asian countries except Malaysia (2.6\%). The reason may be that automated external defibrillators (AEDs) are rarely available in public places or ambulances in Zhejiang province, and not every EMS personnel could operate an AED. Endotracheal intubation has long been regarded as the "gold standard" for cardiac arrest, which may improve outcome in patients who arrest. In our study, pre-hospital intubation was attempted only in $18.1 \%$ patients.

Only ten (3.0\%) patients showed ROSC at scene or en-route and $37(11.1 \%)$ patients showed ROSC at ED. The survival rate to hospital discharge for OHCA victims was low (2.1\%). This overall survival rate was lower than the previously reported rates in countries with developed EMS systems. ${ }^{[9,10]}$ In the future, we can train more people to perform bystander CPR, and introduce AEDs in ambulances and public places.

\section{Limitations}

Our study has limitations. Due to the lack of follow up, we could not ascertain the long-term outcome of patients who survived at discharge. Another limitation is that pre-hospital information was obtained from the EMS records where documentation was inconsistent and incomplete. The third limitation is that the data was only from one hospital and two EMS centers in Zhejiang province.

\section{CONCLUSION}

The OHCA survival in Zhejiang is comparatively low. Several key elements for improving survival rate, like bystander CPR and early defibrillation in OHCA victims, should be emphasized.

\section{Funding: None.}

Ethical approval: The study was approved by the Institutional Review Board.

Conflicts of interest: The authors declare that there are no conflicts of interest regarding the publication of this paper.

Contributors: MF proposed the study, analyzed the data and wrote the first drafts. All authors contributed to the design and interpretation of the study and to further drafts.

\section{REFERENCES}

1 Pei YV, Xiao F. Emergency medicine in China: present and future. World J Emerg Med. 2011;2(4):245-52.

2 Chamberlain D, Cummins RO, Abramson N, Allen M, Baskett $\mathrm{P}$, Becker L, et al. Recommended guidelines for uniform reporting of data from out-of-hospital cardiac arrest: the 'Utstein style'. Prepared by a Task Force of Representatives from the European Resuscitation Council, American Heart Association, Heart and Stroke Foundation of Canada, Australian Resuscitation Council. Resuscitation. 1991;22(1):126.

3 Field JM, Hazinski MF, Sayre MR, Chameides L, Schexnayder SM, Hemphill R, et al. Part 1: executive summary: 2010 American Heart Association Guidelines for Cardiopulmonary Resuscitation and Emergency Cardiovascular Care.. Circulation. 2010;122(18 Suppl 3):S640-56.

4 Nolan JP, Soar J, Zideman DA, Biarent D, Bossaert LL, Deakin C, et al. European Resuscitation Council Guidelines for Resuscitation 2010 Section 1. Executive summary. Resuscitation. 2010;81(10):1219-76.

5 Hung KK, Cheung CS, Rainer TH, Graham CA. EMS systems in China. Resuscitation. 2009;80(7):732-5.

6 Ong ME, Shin SD, De Souza NN, Tanaka H, Nishiuchi T, Song $\mathrm{KJ}$, et al. Outcomes for out-of-hospital cardiac arrests across 7 countries in Asia: The Pan Asian Resuscitation Outcomes Study (PAROS). Resuscitation. 2015;96:100-8.

7 Sasson C, Rogers MA, Dahl J, Kellermann AL. Predictors of survival from out-of-hospital cardiac arrest-a systematic review and meta-analysis. Circ Cardiovasc Qual Outcomes. 2010;3(1):63-81.

8 Song KJ, Shin SD, Park CB, Kim JY, Kim DK, Kim CH, et al. Dispatcher-assisted bystander cardiopulmonary resuscitation in a metropolitan city: a before-after population-based study. Resuscitation. 2014;85(1):34-41.

9 McNally B, Robb R, Mehta M, Vellano K, Valderrama AL, Yoon PW, et al. Out-of-hospital cardiac arrest surveillanceCardiac Arrest Registry to Enhance Survival (CARES), United States, October 1, 2005-December 31, 2010. MMWR Surveill Summ. 2011;60(8):1-19.

$10 \mathrm{Na}$ JU, Han SK, Choi PC, Shin DH. Effect of metronome rates on the quality of bag-mask ventilation during metronomeguided 30:2 cardiopulmonary resuscitation: A randomized simulation study. World J Emerg Med. 2017;8(2):136-140.

Received May 28, 2017

Accepted after revision December 6, 2017 